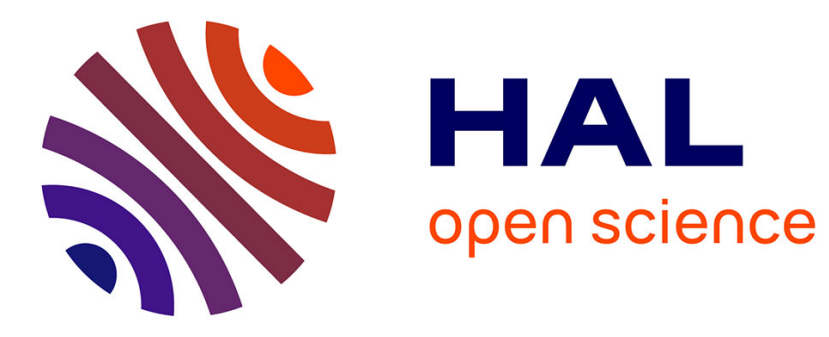

\title{
A Software for Reconstructing 3D-Terrains from Scanned Maps
}

Joachim Pouderoux, Jean-Christophe Gonzato, Pascal Guitton, Xavier

Granier

\section{- To cite this version:}

Joachim Pouderoux, Jean-Christophe Gonzato, Pascal Guitton, Xavier Granier. A Software for Reconstructing 3D-Terrains from Scanned Maps. ACM SIGGRAPH 2004 Sketches, Aug 2004, Los Angeles, California, United States. pp.11, 10.1145/1186223.1186237 . hal-00308004

\section{HAL Id: hal-00308004 https://hal.science/hal-00308004}

Submitted on 29 Jul 2008

HAL is a multi-disciplinary open access archive for the deposit and dissemination of scientific research documents, whether they are published or not. The documents may come from teaching and research institutions in France or abroad, or from public or private research centers.
L'archive ouverte pluridisciplinaire $\mathbf{H A L}$, est destinée au dépôt et à la diffusion de documents scientifiques de niveau recherche, publiés ou non, émanant des établissements d'enseignement et de recherche français ou étrangers, des laboratoires publics ou privés. 


\title{
A Software for Reconstructing 3D-Terrains from Scanned Maps
}

\author{
Joachim Pouderoux, Jean-Christophe Gonzato, Pascal Guitton, Xavier Granier * \\ IPARLA Project (LaBRI - INRIA Futurs) \\ Université Bordeaux 1, France
}

\section{Introduction}

This sketch presents AutoMNT, a software designed for creating Digital Elevation Models (DEM) from scanned color topographic maps for 3D vizualisation and navigation. DEM are used in a large number of civil and military applications. Some operators like USGS in the USA or IGN in France sell DEM data files, but this represents a small database compared to available paper maps for all places over the world at different time periods. The goal is then to create DEM from scanned topographic maps in the most automatic way. Some commercial raster-to-vector softwares (like R2V, WinTOPO, etc.) include tools to help the user in this task, but they are quite limited, and many multi-layers maps need hours of painful manual interventions and corrections. [Arrighi and Soille 1999] described a method based on mathematical morphology but it only works for very clean single layer maps with contour lines only.

\section{Map Processing}

AutoMNT is a software developed in our research laboratory based on a plug-in architecture which already provides many specific filters and tools for DEM creation from maps. Our process is based on contour lines - level curves - extraction and treatment that we divided into 4 main steps:

1. Contour lines extraction from the raster image This step is the most difficult one because of all the other informations that can be drawn or written on the map. The specific color (red/brown) of contour lines is one of the most specific properties we can use, and so we have to solve a problem of color image segmentation. In most of the case a simple range thresholding does not give satisfying results because of noise. Our software proposes to the operator different filters based on fuzzy thresholding, clustering, and neural networks.

2. Contour lines reconstruction Once we have got a binary mask of the input image, the next step consists in reconnecting broken contours. This can be done by thinning contours to get spaghetti-contours in a first time. Then, reconnecting the contours' extremities by using geometrical properties (distances and angles between tangent vectors) or topological features (Delaunay triangulation and crust [Spinello and Guitton 2004]). As this step is crucial for the next ones, a manual inspection is needed to correct eventually missed or bad reconnected contours.

3. Contour lines labelling Once we have the complete and correct level curves, the next step consists in labelling each curve with its elevation. This step is achieved by using GUI tools to set the elevation of some specific contours. Other tools will help the operator to semi-automatically determine the remaining contours' elevation.

4. Contour lines interpolation The last step consists in converting contours to a DEM or a Triangular Irregular Network (TIN). This is achieved by using specific interpolation methods. Our software implements different classical interpolation algorithms using inverse distance weighted averaging, partial differential equations, geodesic distances, absolutely min-

*e-mail:\{pouderou|gonzato|guitton|granier\}@labri.fr imizing Lipschitz extension model, or kriging. Our team also developped a fast hierarchical algorithm [Tobor et al. 2004] for the interpolation of scattered elevation data using radial basis functions.
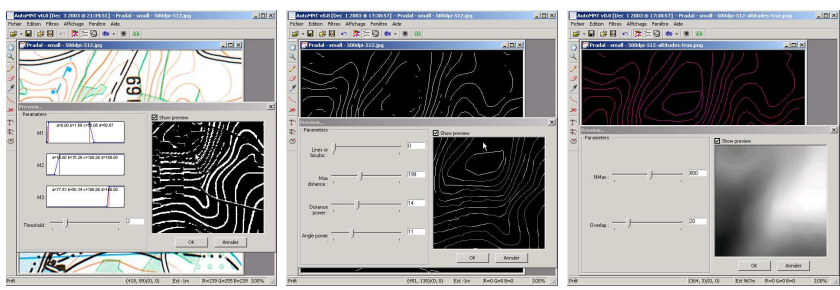

Figure 1: Example of the AutoMNT GUI for steps 1, 2 and 4

AutoMNT ${ }^{1}$ also embeds a terrain viewer and navigator using the Duchaineau's Real-time Optimally Adapting Meshes (ROAM) algorithm (see Figure 2).

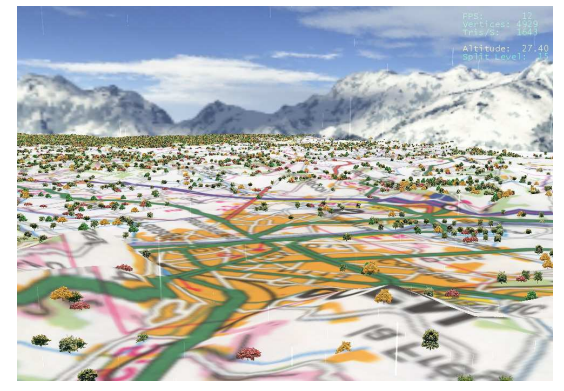

Figure 2: AutoMNT terrain navigator

\section{Conclusions and Future Work}

With our testing maps, the full creation process can takes minutes (instead of hours with classical softwares) but most of this time is loss for manual checking and corrections. Even if we think it's not possible to make this process totally automatic, we think it's possible to enhance the process. We are investigating for new methods, especially for the first step, to get more accurate results and, by the way, make the process more automatic. An algorithm for minimizing the labelling step by using only important contours' elevations (topmost, saddle, etc.) is also in study.

Moreover, our goal is not only to reconstruct the terrain's morphology, but to create complex virtual environments with all information available on the original paper map like rivers, roads, buildings, forest areas, etc. From our first tries, we think that neural networks could give promising results for that task.

\section{References}

ARrighi, P., AND Sollle, P. 1999. From scanned topographic maps to digital elevation models. In Proceedings of Geovision'99.

Spinello, S., AND Guitton, P. 2004. Contour line recognition from scanned topographic maps. Journal of WSCG 12, 3.

Tobor, I., Reuter, P., AND Schlick, C. 2004. Multiresolution reconstruction of implicit surfaces with attributes from large unorganized point sets. In Shape Modeling and Applications'04.

\footnotetext{
${ }^{1}$ http://iparla.labri.fr/softwares/automnt
} 